\title{
A Multimodal Discourse Analysis of English Posters in Violence Awareness Campaigns against Women
}

\author{
Souad Belgrimet \\ The University of Jordan, Jordan \\ Ghaleb Rabab'ah \\ The University of Sharjah, UAE
}

\begin{abstract}
The present study seeks to delve into the intricacies of multimodal discourse analysis with regard to violence against women awareness campaign posters. To this end, a study is conducted on English posters. In this respect, the different semiotic modes adopted in English posters were put under scrutiny. Similarly, the study attempts to explore how the adoption of different semiotic modes may contribute to the construction of meaning when cooperating with language. To this end, three English posters were selected from different electronic sources and put under investigation. The qualitative analysis of the yielded results was couched with Kress and Van Leeuwen's (2006) Visual Grammar framework. The findings indicate that English posters employed a variety of semiotic modes. By the same token, the yielded results indicate that the majority of the sampled posters are conceptual. Such visual characterization demonstrates that the English posters tend to be static and immovable.
\end{abstract}

Index Terms-multimodal discourse analysis, awareness campaigns on violence against women, English posters, visual grammar

\section{INTRODUCTION}

The study of language has long been a matter of great interest for linguists in particular and the large public in general. Accordingly, a number of approaches came to the fore bringing about new instances of the different uses and functions of language. However, in recent years, a new approach to the study of discourse has taken center stage, namely: Multimodal Discourse Analysis (MDA). In fact, although the multimodality of discourse has received a fair bit of attention long time ago, scholars have only realized its importance quite recently. Such interest reached its peak with the pioneering work of the two forerunners of multimodality: Kress and Van Leeuwen. Indeed, in 1996, they developed a theoretical framework well known as "Visual Grammar" or "Grammar of Visual Design" further developed in 2006. At the core of this theory is the belief that although language is a very important resource in discourse, yet it needs to coordinate with other resources in the process of meaning-making.

As explicitly evinced by Van Leeuwen (2015), multimodality was adopted and investigated in a range of disciplines: advertisement, health communication, mass media, political discourse, movies and education. As far as educational discourse is concerned, the New London Group stimulated an interest in applying multimodal analysis to education. Such interest paves the way to the development of different types of multimodal studies. Among these, the studies dealing with the development of literacy in young children. Such studies were conducted with an eye towards the inclusion of multimodal literacy in the curriculum such as the call for integrating both receptive and productive skills. In a similar standpoint, some studies casted light on the learning resources as their point of departure. That is, the emphasis was on whether a single learning instrument is used or different instruments such as textbooks, internet, and toys are combined and adopted to promote the teaching/learning process.

Another type of multimodal studies dealing with education revolves around multimodal classroom interaction. The latter involves a shift of emphasis from the traditional focus on the grammatical structures exchanged during interaction to the contextual patterns and scrutinized attention to nonverbal communication and setting.

In this regard, the paper at hand seeks to throw light on the set of semiotic modes employed in English posters dealing with violence against women. Being a major construct in the present study, it seems important at the outset to cast light on the different aspects of such a phenomenon. In fact, in the United Nations Declaration of the Elimination of Violence against Women (VAW) that took place in 1993, VAW was defined as a health and human issue resulting from gender-based violence. The latter appears to have both physical and psychological harms on women. Similarly, such violence may take place in social or private contexts.

From another perspective, upon trying to delve into the intricacies of awareness campaigns, Lamb (1997) defined an awareness campaign as any conscious, purposeful effort aimed at targeting a given audience and therefore raising their awareness towards a given phenomenon and highlighting the dire need to take action. By doing so, public pressure is meant to increase in order to change and improve the behavior of individuals and institutions. In a similar standpoint, 
when dealing with awareness campaigns preventing VAW, Coffman (2003) distinguished between two major types of awareness campaigns based on the audience they target. The first type of awareness campaigns is aimed at institutional and policy change. In this respect, the aim behind the launching of such campaigns is to introduce more powerful and compelling policies to prevent a given issue. The second type of awareness campaigns tends to be more specific as it targets individuals and the set of deep seated social norms which have a negative impact on a given phenomenon.

\section{A. Research Objectives}

The present study aims to bring new insights and enrich the existing literature on multimodality with a special focus on awareness campaigns dealing with violence against women. Accordingly, the study aims to:

1. Highlight the different semiotic modes adopted in English posters.

2. Explore how the different semiotic modes employed in each poster (both linguistic and paralinguistic) are combined in order to convey a given meaning.

\section{B. Research Questions}

In order to frame and guide the present study, the following research questions are devised:

1. What are the different semiotic modes adopted in English posters?

2. How do these semiotic modes contribute to the deployment of the intended meaning in each poster?

\section{LITERATURE REVIEW}

In the last couple of decades, intensive scrutiny was devoted to the investigation of multimodality. Accordingly, different multimodal pieces of discourse were put under investigation in a range of disciplines and in diversified genres. Relatively, it seems important at the outset to shed light on some key concepts.

\section{A. Semiotics}

Semiotics is a subfield of linguistics. In an attempt to define semiotics, Chandler (2002) holds that although the majority of semioticians show agreement regarding the basic definition of semiotics as the study of signs, there is apparent alternation as to what the study of semiotics exactly comprises. Relatively, Eco (1976) states that "semiotics is concerned with everything that can be taken as a sign" (p.7). Chandler (2002) claims that it is a prerequisite to comprehend the concept of signs as the latter seems to lie at the real heart of semiotics. Signs are said to be the different visual information we come across in our daily lives such as road signs and advertisement signs. Such definition opens up a path for the assumption that signs solely include visual information. However, Chandler (2002) addresses this deep-seated misconception by highlighting that semiotics includes visual signs such as figures, drawings and paintings as well verbal signs including "words, sounds and body language" (p. 2).

\section{B. Multimodality}

Multimodality is viewed as a phenomenon rather than a theory (Van Leeuwen, 2015). In fact, all kinds of discourse are said to be multimodal. Spoken discourse for instance characterizes the combination of language, intonation, voice quality, gestures, facial expressions and posture in addition to some aspects of self representation such as dress and hairstyle. Written discourse on the other hand includes the combination of language, typographic expressions, illustration, layout and colour (ibid). Such intensive scrutiny was motivated by the belief that investigating different types of semiotic modes that occur in a given piece of discourse and looking at how these modes combine has the promise of deploying different ideologies and hidden beliefs (Van Leeuwen, 2015). Accordingly, a number of frameworks emerged to analyze the multimodality of different types of discourse. Among these is the Visual Grammar paradigm developed by Kress and Van Leeuwen in 1996 and modified in (2006). The latter will be adopted in the present study.

\section{Visual Grammar Paradigm}

Visual Grammar or Grammar of Visual Design (also called metafunctional framework) is a framework developed by Kress and Van Leeuwen. It is noteworthy though that the first version of the framework appeared in 1996 and was modified in 2006. In essence, their paradigm was developed to deal with the analysis of images. Their work can be considered as an adaptation of Halliday's Systemic Functional Grammar in which he considered the different metafunctions of language. The latter included three main metafunctions: the ideational, the interpersonal and the textual. As for the ideational metafunction, Halliday argues that "any semiotic mode has to be able to represent aspects of the world as it is experienced by humans" (Kress and Van Leeuwen, 2006, p. 42). In other words, language is a characterization of what is found in the real world. The interpersonal metafunction on the other hand explores the existing relationship between the producer of a given sign, the sign and the receiver of the sign. Finally, the textual metafunction of language deals with the cohesive devices used to convey a given message (Kress and Van Leeuwen, 2006). In their Grammar of Visual Design developed for the analysis of images, Kress and Van Leeuwen (2006) distinguished between three different types of meaning (also called metafunctions), namely, representational, interactive and compositional. 
To start with, the representational metafunction of signs includes three main elements: processes, participants and circumstances. First, the processes encompass both narrative and conceptual processes. Indeed, the narrative process tends to occur in images which exhibit a given action best known as a "vector" while the conceptual process is more likely to be found in images which lack action. In this regard, Kress and Van Leeuwen's (1996) work was stimulated by Halliday's transitivity theory. In fact, in his analysis of clauses, Halliday (1994) included three main elements, namely, participants, processes and circumstances. Accordingly, participants were expressed via nouns and pronouns, processes were conveyed by means of verbs and circumstances by the use of time and place adverbs. This framework was adapted in 1996 in a pioneering work conducted by Kress and Van Leeuwen who modified Halliday's framework in such a way that meets the analysis of images. In this respect, Halliday's participants were paralleled with volumes, the processes with vectors and finally the circumstances were paralleled with the setting or the background (Van Leeuwen, 2015). In line with Kress and Van Leeuwen's Visual Grammar framework (2006), the participants are divided into represented participants who are generally included in the images and the interactive participants who consist of the image designer and the viewer of the image. Finally, circumstances in the Visual Grammar framework encompass locative circumstances that are in turn divided into the analysis of the foreground and the background. Circumstances similarly comprise circumstance of means which indicates the kind of relationship involved in the image.

On the other hand, the interactive metafunction includes different elements: the image act and gaze, size of frame and social distance, perspective and modality. In this respect, the image designer has the possibility of including the visual element of gaze in a given image so that this image may be regarded as a "demand" image or an "offer" image in case the visual element of gaze is not included in the image. As for the size of frame, the designer may adopt a close shot which characterized by the distance in which one participant may hold or grasp another participant. Such distance may be regarded as an indication of the existing relationship between the participants themselves and the participants and the audience. Second, perspective refers to the point of view or angle from which an image is produced. The selection of a given angle is said to express a subjective attitude that should be explored. As far as modality is concerned, it refers to the degree to which a given image is real and authentic. Accordingly, assessing the modality of a given image involves the consideration of different factors such as colours, contextualization and representation.

Finally, the compositional metafunction comprises three main elements: information value, salience and framing. Information value is concerned with the "placement of elements" in a given image (Kress and Van Leeuwen, 2006, p. 177). Salience refers to the analysis of the elements which mostly attract the attention of the reader. These may be deduced from colors, the size of elements and their position in relation to the background and foreground. Finally, framing refers to whether the elements found in pictures are put together or separated.

\section{Previous Studies on Multimodality}

A flurry of studies was conducted as the field begins to flower in order to shed light on how different semiotic modes are combined to express meaning.

With the intent of analyzing the multimodality of political posters launched for the Irish campaign of Fianna Fail political party, Lirola (2016) undertook a multimodal discourse analysis of a number of political posters in Ireland during and after the Celtic Tiger. Such an analysis was conducted with an eye towards the changes in the political posters launched during the Celtic Tiger (between 1997 and 2008) and those launched in the post Celtic Tiger period (2009-2012). Relatively, four posters were put under investigation. These were launched on different occasions in which different elections took place (1997, 2002, 2007 and 2011). The analysis of the posters was aimed at delving into the set of similarities and differences between the range of posters and the representation and depiction of leader. The latter seems to play a significant role in understanding how designers combine verbal and visual modes to give a certain characterization regarding the power of the party or candidate into question which consequently contribute to the persuasion of the audience to vote for that party. By the same token, the data analysis was couched within the framework of Critical Discourse Analysis to uncover the persuasive strategies adopted in the posters under scrutiny. Similarly, the Social Actor theory developed by Van Leeuwen (2008) and Kress and Van Leeuwen's Visual Grammar (2006) were employed to analyze the visual dimensions of the posters and identify how different participants are depicted and represented. The findings of the study shed light on the positive representation attributed to leaders and politicians whose status and formality were sketched. These are regarded as significant factors which play a crucial role in spotting light and foregrounding the power and potential of a given party and thus persuading the audience to vote in a given direction.

From another perspective, Al-Masri (2016) adopted a multimodal stance to analyze the Jordanian cartoon editorials drawn by Emad Hajjaj. Accordingly, she adopted a multimodal stance in her attempt to uncover the different messages delivered in the cartoons under scrutiny. To this end, 300 cartoons were investigated. The analysis was couched within Van Dijk's (2008) theory of context models. In this regard, the researcher analyzed both the verbal and non-verbal modes found in the editorial cartoons by taking into consideration three different types of contexts that appear to be fundamental for the understanding of the cartoons' messages. These include the macro context, micro context and dynamic context. The findings of Al-Masri's study tease out the fact that Emad Hajjaj adopts a combination of the verbal, visual and sociocultural dimensions to deploy different messages in his cartoons which project socioculturally pertinent issues. 
By the same token, Hu and Luo (2016) conducted a multimodal discourse analysis of the double eleven shopping carnival advertisement produced by Tmall. In this respect, the researchers adopted Kress and Van Leeuwen's initial framework of Visual Grammar (1996) developed to analyze the visual dimensions of discourse. At the core of the research interest was the desire to make explicit how the different semiotic resources employed in advertisement may serve as an attraction and persuasion means. The results demonstrate that the operation and combination of the representational, interactive and compositional meanings played a significant role in persuading the audience and rationalizing their behavior. The study similarly divulges the different strategies that advertisement designers employ in order to psychologically manipulate control and influence the audience.

An example of a multimodal study focusing on media is the one conducted by Tan et al. (2018) who attempted to investigate how violent extremist images are recontextualized in online media. In fact, the study sought in essence to throw light on the kind of images adopted and created by ISIS (Islamic State of Iraq and Syria) which are most frequently readopted in other online media. Similarly, it attempts to explore the different contexts in which these images are readopted and whether such contexts are formal or informal. That is, it explores the reuse of such images in other different media platforms such as news websites and blogs. To this end, the researchers adopted a mixed approach in which a variety of data analysis methods were employed. These include: multimodal discourse analysis, data mining and information visualization. It is worth mentioning that the study reports on the prior findings of a study exploring the re-adoption of the images found in ISIS magazines such as Dabiq and Rumiyah. The findings indicate that some images do indeed exhibit some recontextualisation aspects. As for the contexts in which such images are reused, the results revealed that the images are mainly found in western news and politics websites most frequently in formal contexts.

\section{METHOD}

\section{A. Sample and Data Collection}

In an attempt to answer the aforementioned research questions, a total of three English awareness campaign posters dealing with violence against women were put under scrutiny. Accordingly, the data were selected from different electronic sources based on availability. In this regard, the English posters were selected from some foundations' Instagram accounts, namely, unwomencanada, unwomenuk and unwomen. In fact, it is worth mentioning that the selection of the posters was based on the language of the caption provided. In this regard, the posters encompassing English captions are said to reflect the awareness campaigns launched in the context of the English-speaking countries.

\section{B. Data Analysis}

With the intent of answering the first and second research questions, a scrutinized qualitative analysis was conducted for each poster in each language using the Visual Grammar paradigm developed by Kress and Van Leeuwen (2006). Accordingly, the researcher identified the different semiotic modes that constitute each poster (both linguistic and paralinguistic).That being so, the posters were analyzed with regard to the three meatfunctions, namely, representational, interactive and compositional. Moreover, to maximize the validity and reliability of the results to be obtained, the foundation launching each awareness campaign was specified, that is, the researcher described the source from which each of the sampled posters was extracted (see appendix 1 p. 23). For English posters, the researcher made sure that the countries in which the foundations were located are English-speaking countries.

\section{RESULTS AND DISCUSSION}

\section{The Semiotic Modes adopted in English Posters and their Deployment of Meaning:}

The present section seeks to answer the first and second research questions. As such, Kress and Van Leeuwen's (2006) Visual Grammar framework was employed to identify the different semiotic modes adopted in the three English posters. It similarly attempts to cast light on how the employment of these semiotic modes contributes to the construction of meaning.

\section{The Representational Metafunction:}

a. The Participants:

A look at the three English posters put under scrutiny indicates that they all include represented participants. By way of illustration, poster one (see appendix 2 p. 23) encompasses two represented participants, a man and a woman. Accordingly, the woman is on the left and is distinguished by her dress. The two represented participants are displayed in white and exhibited as being equal. That is, no actor or goal is displayed in the poster due to the absence of a dynamic vector. The only relation that seems to be shared between the two represented participants is that of equality. From another perspective, the interactive participants are the audience to whom the poster is directed.

Alternatively, poster two (see appendix 2 p. 24) incorporates only one represented participant displayed as a woman wearing a dress. A closer look at the poster evinces the absence of vectors in the poster as no action is displayed. Accordingly, the represented participant may neither be considered as an actor nor a goal. The absence of gaze in the poster similarly eliminates that postulation of the represented participant as being a "phenomenon" according to Kress and Van Leeuwen's (2006) terminology. 
Poster three (see appendix 2 p. 24) shows that only one represented participant is included. The represented participant is the famous American actress Emma Watson, the UN Women Goodwill Ambassador as mentioned at the bottom of the poster on the right side. In this regard, the one represented participant plays the role of "actor". Relatively, Kress and Van Leeuwen (2006) argued that when a given image encompasses only one represented participant, this participant is considered as an actor. In fact, it seems tempting to assume that the represented participant in the poster, namely, Emma Watson is addressing the audience by means of her gaze. Such an assumption lends further support to Kress and Van Leeuwen's (2006) idea that the represented participant in the poster under scrutiny is an actor.

As far as the interactive participants are concerned, these consist of the audience to whom the three investigated posters are directed.

\section{b. The Processes:}

With the intent of analyzing the set of processes involved in the English posters on violence against women, it seems that two main processes are involved, namely, conceptual and reactional. Accordingly, poster one and two encapsulate a conceptual process. Relatively, the non presence of vectors in poster one and two makes them more static and timeless (Kress and Van Leeuwen, 2006). Accordingly, as for poster one, the displaying of a conceptual process explains the absence of actor and goal for the characterization of man and woman. In the present poster, the only visual information provided about the represented participants is equality between men and women. In this regard, being a man or a woman is a timeless, steady, and fixed fact.

Poster two does not exhibit a dynamic action in which one represented participant performs a given action on the other. As such, the poster may not be considered as encompassing a narrative process. On the other hand, the absence of the visual element of gaze on the part of the represented participant eliminates the assumption of having a reactional process in the poster. As a result, the poster appears to carry a conceptual process in which a static and timeless representation is displayed which is the case in the poster under scrutiny. In brief, such visual configuration brings forth the stability, invariability and steadiness of the poster.

However, poster three includes a reactional process. Such a process is realized when the vector consists of an eyeline or gaze of a given represented participant. By the same token, the represented participant and her gaze form "the phenomenon" while the interactive participants are the "reactors" using Kress and Van Leeuwen's (2006) terminology.

\section{c. The Circumstances:}

Circumstances are divided into locative circumstances and circumstances of means. The locative circumstances revolve around the background and foreground provided in the posters. However, the circumstance of means deals with the different means adopted in action processes. Such circumstances may be circumstances of accompaniment. In addition, although the presence or absence of visual element of gaze responsible for classifying a given poster as a "demand" or "offer" poster is more related to the interactive metafunction, it may sometimes be related to the representational metafunction as it sometimes enhances the context of the image and consequently promotes meaning . In this regard, poster one shows that two types of information are displayed: pictorial and verbal. The pictorial information is characterized by the two represented participants located on the right part of the poster. However, the verbal information is located on the left part of the poster. These two types of information are foregrounded against a black background. Such a characterization makes them more visible to the audience. By doing so, it is suggested that the viewers will become more inclined to consider the content of the poster and consequently react to it. Second, a glance at the poster indicates the absence of the circumstance of means. Indeed, as shown in the poster,

As far as the locative circumstances of poster two are concerned, it is demonstrated that the represented participant is positioned next to a paper which seems to be a legal decree and a court room hammer. The paper and the court room hammer signal the field of law. Such interpretation is further strengthened by the caption at the bottom of the poster which indicates the need for making changes in the field of law regarding women's rights. The caption is: (Transform. Transform the culture by enforcing laws that protect women's right and changing the attitudes that condone violence against women). As may be seen, the caption employs the imperative mood which implies that the caption calls for action and involvement on the part of the legal authorities on the first hand and the audience on the other hand. In a similar standpoint, the represented participant, the legal decree and the court room hammer are put against an orange background. As previously stated, the orange color is a representation of the awareness campaign of the 16 days of activism against gender-based violence which indicates the occasion on which the poster was launched. In much the same way as poster one, poster two includes no circumstance of means.

In an attempt to analyze the locative circumstances of poster three, it appears that the participant is located in the foreground against a grey background and the setting is lighter than the foreground. The aim of such representation seems to be the desire to highlight the main represented participant in the poster with her gaze towards the audience. In fact, by positioning the participant in the foreground with darker shades of grey and black, it becomes the most eyecatching component in the poster. Consequently, the audience is believed to become more tempted to react to the participant's gaze. By the same token, gaze is considered as a circumstance of means, i.e., the gaze itself may be regarded as the vector which realizes the reactional process.

Simply worded, the pronoun (we) used in the caption indicates that the represented participant is addressing the audience to work together in order to stop violence against women. This seems to be realized via her gaze and 
reinforced by the use of the pronoun (we) in the caption which indicates that the represented participant identifies herself with the audience as being both involved in the mission of stopping violence against women.

This visual configuration fulfills two main functions: first, it explicitly addresses the audience through gaze and the use of the pronoun (we). Relatively, the poster indicates that the represented participant looks at the viewers from a short distance. This fact greatly augments the effect of her look. Second, the poster may be regarded as an "image act" as the producer of the poster aims to reach a given objective by designing the poster. This kind of images is consequently called "demand" images in Kress and Van Leeuwen's terms (2006). In a similar standpoint, the type of the existing relationship between the represented participants and the viewers may be inferred based on different parameters. In the case of the present poster, the represented participant seems focused and determined and may consequently express the dire need to take action and stop violence against women. It is worth pointing out that the notions of offer and demand are intricately intertwined with the linguistic concept of speech acts. Indeed, speech acts are realized by the linguistic system of mood. The caption (We want to end gender inequality-and to do that we need everyone to be involved) found in the poster has the indicative mood where the finite element follows the subject.

\section{The Interactive Metafunction:}

\section{a. The Image Act and Gaze:}

The image act and gaze constitute the first element of the interactive metafunction in Kress and Van Leeuwen's (2006) Visual Grammar framework. In fact, the presence or absence of gaze is said to determine whether the image fulfills the act of "demand" or "offer". Relatively, in poster one, the two represented participants' facial expressions are missing. As a result, no gaze is directed to the audience. On these grounds, it may be claimed that the poster is an "offer" poster. Accordingly, poster one only offers information about the criterion that an individual should meet in order to be a HeforShe as mentioned in the caption: (Are you a HeForShe? A HeForShe believes that gender equality is a human rights issue that affects all of $u s$ ). In a similar vein, the represented participants who are separated by an equal symbol (=) are believed to reinforce the caption on the left part of the poster.

In much the same way as poster one, the visual element of gaze is not sketched in poster two. Bearing this in mind, it may be concluded that the poster falls under the category of "offer" posters in which the aim of the poster is to provide information about a given issue (Kress and Van Leeuwen, 2006). Accordingly, the present poster only provides information about the role of legal authorities in promoting women's rights.

Alternatively, poster three incorporates the visual element of gaze. As such, the represented participant appears to be aiming at conveying a given message by means of her gaze. In this regard, the participant's gaze is translated in the caption: (We want to end gender inequality-and to do that we need everyone to be involved).

\section{b. Size of Frame and Social Distance:}

From another perspective, it is suggested in the Visual Grammar framework (Kress and Van Leewuen, 2006) that the selection of distance may be an indicator of the social distance between the represented participants and the audience. In this respect, a glance at the three English posters evinces that only poster three exhibits a close shot also referred to as "close-up" in which only the head and shoulders of the represented participant are sketched to the audience. Such depiction indicates that the represented participant is close to the audience. On these grounds, it may be argued that the poster designer's aim was to highlight the dire need to encourage the cooperation and unity between the community members to engage in the process of stopping violence against women.

Alternatively, poster one and two do not exhibit a close shot as the represented participants are fully displayed to the audience. The non-adoption of a close shot may be explained by the fact that the two posters are "offer" posters which only provide information and not demand posters which requires the represented participants to be close to the audience. By the same token, the shot adopted is a signal of social distance (Kress and Van Leeuwen, 2006). Accordingly, the absence of a close shot indicates the absence of a close relationship between the represented participants and the audience. One argument that may be brought forth in support of this assumption is the fact that the represented participants are only a characterization of individuals but not real ones. Thus, the represented participants sketched in the poster are not human and are consequently kept anonymous to the audience. As such, the members of the audience are not able to build a relationship with unknown, nonhuman individuals.

\section{c. Perspective:}

Perspective refers to the angle selected by the designer of the poster to convey a given meaning. A glance at the English posters put under investigation teases out that they all exhibit a frontal angle. When investigating the rationale behind the use of a frontal angle instead of an oblique one, it is noteworthy that the difference between frontal and oblique angles is paralleled with the difference between "involvement" and "detachment" (Kress and Van Leeuwen, 2006). As may be seen, the adoption of a frontal angle is not random. It is aimed at making the audience involved with the represented participants to eradicate the social phenomenon of violence against women. In a similar vein, it is worth pointing out that the image is at eye level; this implies that no power difference is manifested between the represented participants and the audience (Kress and Van Leeuwen, 2006).

d. Modality:

As far as modality is concerned, a number of parameters are taken into consideration when analyzing the degree to which a given picture is real and naturalistic. These are: colours, contextualization, representation, illumination, and brightness. As far as the colours used with poster one are concerned, it appears that the choice of colours employed 
lowers modality. In this regard, the white colour is used with the represented participants eliminating by doing so all details about their face and body. Indeed, details about their facial expressions, their gaze, their skin and hair colours, and the colour of their clothes are not displayed in the poster.

In a similar fashion, the colours used in poster two considerably lower the modality of the poster. The visual elements are displayed in white and orange. Such characterization dismisses many details about the real state of elements. A case in point is the represented participant. Accordingly, the white color used for displaying it conceals many details such as the skin and hair colours, the colour of her eyes and dress. Similarly, it eliminates the facial expressions and the gaze of the represented participant. Similarly, only two colours are used with poster three, namely, black and white with some shades of grey. Taking into account the role of color as a marker of naturalistic modality, it appears that this use of colors reduces modality as it may be considered as less than real as it is less saturated. Thus, it may be concluded that modality is low in the sampled English posters with reference to colours.

Second, as for the contribution of context in making the posters more naturalistic and real, it appears from the posters that no contexts were provided. In fact, the represented participants are foregrounded against a black background in poster one and against an orange background in poster two. However, in the third poster, the represented participant is displayed against a gray background. As a result, it may be argued that the non-presence of contexts in the sampled posters lowers modality.

Third, as far as representation is concerned, it seems to be remarkably lacking in posters one and two. Accordingly, the posters indicate that many details about the represented participants such as: their facial expressions and the feelings they carry, their skin and hair colours and their gaze are missing in the poster. However, it seems tempting to assume that poster three is naturalistic and exhibits many details concerning the represented participant such as her facial expressions, haircut and gaze.

Forth, in an attempt to examine the illumination provided in the posters, it seems that illumination is only present in poster three mostly apparent in the left side of the represented participant's face. However, such illumination seems to be lacking on the right side of the represented participant's face. As such, the depiction of the represented participant may be said to have moderate degree of modality as there is a source of illumination on one side but not on the other. However, illumination appears to be completely lacking in posters one and two since none of the elements provided in the posters is illuminated. As such, the non- provision of illumination significantly decreases the modality of posters one and two.

Finally, as for the brightness values provided, these appear to differ to a great extent in poster one and two as different colors are used instead of using different shades of the same color which is the case in poster three. As may be seen, judging the modality of a given image is realized based on the interplay of a number of parameters. Consequently, an image may be naturalistic in terms of one marker and abstract in terms of another.

\section{The Compositional Metafunction:}

\section{a. Information Value:}

The three posters demonstrate that two types of information are included, namely, verbal and pictorial. In poster one, the verbal information is sketched on the left part of the poster while the pictorial information is on its right side. As previously mentioned, the "left" and "right" distinction is paralleled with "given" and "new" information respectively (Kress and Van Leeuwen, 2006). To put this fact on a concrete footing, it seems tempting to assume that the caption: (Are you a HeForShe? A HeForShe believes that gender equality is a human rights issue that affects all of us) is the "given" information while the represented participants on the right part of the poster represent the "new" information. Such a classification goes in line with the coding orientation of the English language that goes from left to right. Relatively, the caption on the left side of the poster represents the "given" information that all men who care about women's rights are supposed to know. Conversely, the represented participants on the right side of the poster constitute a concrete displaying of the equality that exists between men and women and consequently complements the caption on the left side of the poster.

From another perspective, a glance at poster one shows that additionally there is a "top" and "bottom" distinction that is paralleled with the "ideal" and "real" distinction respectively (Kress and Van Leeuwen, 2006). In this respect, the caption displayed in pink at the very bottom of the poster is the real. That is, what is real is the fact that all individuals are born equal regardless of their gender. However, such a fact is not always respected by all individuals in reality as women's rights are violated in many domains. However, the represented participants' characterization at the top of the poster indicates what is supposed to exist in reality or the ideal which is explicitly indicated by the use of the sign equal (=) which communicates the kind of relationship that should exist between men and women. Thus, it may be concluded that the characterization of the represented participants at the top of the poster complements the information provided by the caption at the bottom of the poster.

In poster two, the caption at the bottom of the poster constitutes the verbal information while the represented participant, the legal decree and courtroom hammer on the top of the poster represent the pictorial information. In this regard, the poster seems to embody the real/ideal distinction highlighted by Kress and Van Leeuwen (2006). According to them, the information at the bottom of a given poster is the "real" while the information located on the top of the poster is the "ideal". To put such idea on a concrete footing, it seems plausible to suppose that the caption only provides information about the calls of many foundations for gender equality and the preservation of women's rights. 
Accordingly, the call for women's rights preservation is one of the foundations' goals. Such a fact is displayed in reality which explains the positioning of the caption at the bottom of the poster. On the other hand, the pictorial elements represented on the top of the poster may be regarded as the "ideal" since they explicitly exhibit the link between the legal authorities and women. As a matter of fact, such characterization clearly and explicitly demonstrates the need for such authorities to make changes in order to promote women's rights. Thus, it may be concluded that the pictorial information is only an explicit and concrete realization of what should be realized in real life.

Finally, poster three shows that the image is divided into two parts by a boundary. The left part, which is larger than the other parts, includes a photo of the represented participant Emma Watson. On the other hand, the right part of the poster includes the verbal text or the caption. In this case the two parts convey two different types of information: given and new. In this regard, the "new", key information that the reader should pay attention to is situated on the right. However, what the viewer already knows and is familiar with is located on the left side and is best known as "given" information that is supposed to be grounded in the audience's culture. As such, it might be claimed that Emma Watson's photo on the left is the given information, and the point of departure which paves the way for the new information (i.e., the message on the right) to be conveyed. With the intent of analyzing such a fact, it might be claimed that Emma Watson is an American public figure that is well known worldwide. Thus Emma Watson's face is considered as given information. However, what might not be known to many of her followers is that she became an activist for women's rights. This was conveyed by means of her message on the right side of the poster: (we want to end gender inequality-and to do that we need everyone to be involved). Accordingly, the message on the right side is considered as the new information that the audience should pay particular attention to. It is noteworthy though that this coding orientation is different from one culture to another.

\section{b. Salience:}

In an attempt to determine the most salient element in a given image, a number of factors are worth consulting. These are: size, sharpness of focus, colour contrasts and placement in the visual field. Accordingly, the most salient elements in posters one and three are the represented participants. Such a fact may be explained on a number of grounds. In fact, the represented participants in poster one are located in the foreground and take the largest part and especially because they are in sharper focus. The represented participant in poster three similarly receives the greatest amount of light. Moreover, the colours used for representing them outstandingly make them noticeable and attractive especially that they are foregrounded against a black and gray background. Nonetheless, the caption "TRANSFORM" is the most salient element in poster two. The rationale behind such a claim is the fact that it is positioned at the center of the poster. In addition, it is written in capital letters in a bold font. Such characterization is also foregrounded against an orange background making the caption more apparent and attractive to the audience. In addition, the represented participant, the legal decree and courtroom hammer are the second most salient element in the poster. First, as clearly sketched, an important space is provided to them in the poster. Also, the white and grey colors used contribute to their salience especially when positioned against the orange background.

\section{c. Framing:}

Framing refers to the degree of connection that exists between the different elements that form the composition. The more these elements are connected to each other, the more likely they are to convey the same information. it seems plausible to assume that though the different types of information presented in poster one and three are included within separate frames (i.e., a black square in poster one), they all seem to convey the same meaning as the distance between frames is not significant. Thus, all elements included in the poster revolve around one main issue which is men's and women's equality.

However, poster two demonstrates that both the pictorial and verbal elements are included within the same frame. As such, there is no frame that separates between one information and the other. As a result, both types of information convey the same meaning. This supposition brings forth support for the previously evinced idea that each type of information complements the other.

\section{CONCLUSION}

In the last couple of decades, ample attention was pointed to the study of multimodality as a new trend holding the promise of providing more in depth results with regard to the analysis of different types of discourse. Accordingly, the present paper was intended to delve into the intricacies of a yet neglected kind of discourse, namely: awareness campaigns. Relatively, the study primarily attempted to explore English posters dealing with violence against women. To this end, a multimodal stance was espoused. Correspondingly, the analysis of the set of semiotic modes adopted was couched within Kress and Van Leeuwen's (2006) Visual Grammar framework which incorporates three major metafunctions: representational, interactive and compositional each encompassing a set of subcategories. Furthermore, the study tried to examine the ways in which the incorporation of different semiotic modes, both visual and textual contributes to the deployment of meaning in the posters put under scrutiny. The yielded results indicate that the English posters include verbal as well as visual elements which contribute to the deployment of meaning. That being so, a pure qualitative study was conducted to reach these two objectives.

Regarding the representational metafunction, all scrutinized posters exhibited the presence of participants. Nonetheless, it is noteworthy that the majority of English posters are conceptual and consequently lack dynamicity. 
Finally, circumstances were characterized by the presence of locative circumstances in the three investigated posters as each and every poster comprised a foreground located against a given background. In a similar vein, circumstances of means proved to be only present in the third poster and conveyed by means of gaze.

Second, as far as the interactive metafunction is concerned, it similarly includes a set of major subcategories. With regard to the image act and gaze, only poster three included the visual element of gaze and was consequently regarded as "demand" poster. Alternatively, posters one and two lack gaze and are consequently viewed as "offer" posters. Second, as for the size of frames included and their relation to social distance, the yielded results indicated that both close and long shots were adopted with the prevailing use of long shots as an indicator of a non-close social distance existing between the audience and the represented participants. Additionally, as far as perspective is concerned, the analysis disclosed that the majority of posters adopted a frontal angle that signals involvement in line with Kress and Van Leeuwen's (2006) terminology. Ultimately, as for modality, it may be claimed that in much cases, modality was moderate as it was high with reference to some factors but not to others.

Third, concerning the compositional metafunction both left/right and top/bottom information values were found in the posters. As for salience, the results obtained tease out the fact that in most cases, the represented participants comprised in the posters were the most attractive, eye-catching element. Finally, the use of frames in the posters put under scrutiny proved not to affect the meanings and messages conveyed in the posters as the frames solely included information related to the foundation and the awareness campaign launching the poster or the caption of the poster.

\section{APPENDIX 1. INFORMATION RELATED TO THE SAMPLED POSTERS}

TABLE 1

The Awareness CAmPaign English Posters On Violence Against Women

\begin{tabular}{ccccc}
\hline English posters & Foundation & Awarenesscampaign's name & Year & Country \\
\hline Poster one & unwomencanada & HeforShe & 2014 & Canada \\
Poster two & unwomenuk & 16 days of activism against gender-based & 2019 & United Kingdom \\
Poster three & unwomen & We want to end gender inequality & 2019 & USA \\
\hline
\end{tabular}

\section{APPENDIX 2. ENGLISH POSTERS}

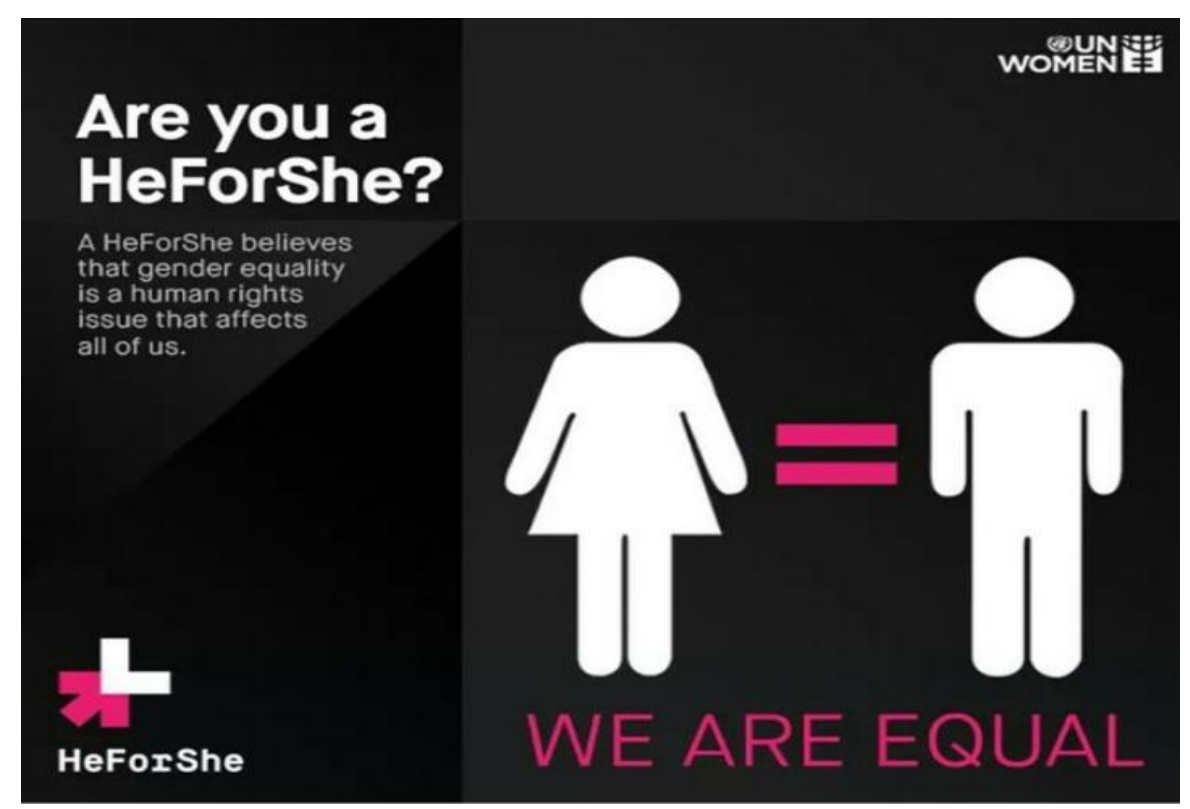

Poster 1. https://www.instagram.com/p/uTA-V2iil5/?igshid=1aawd1s5ft33s 


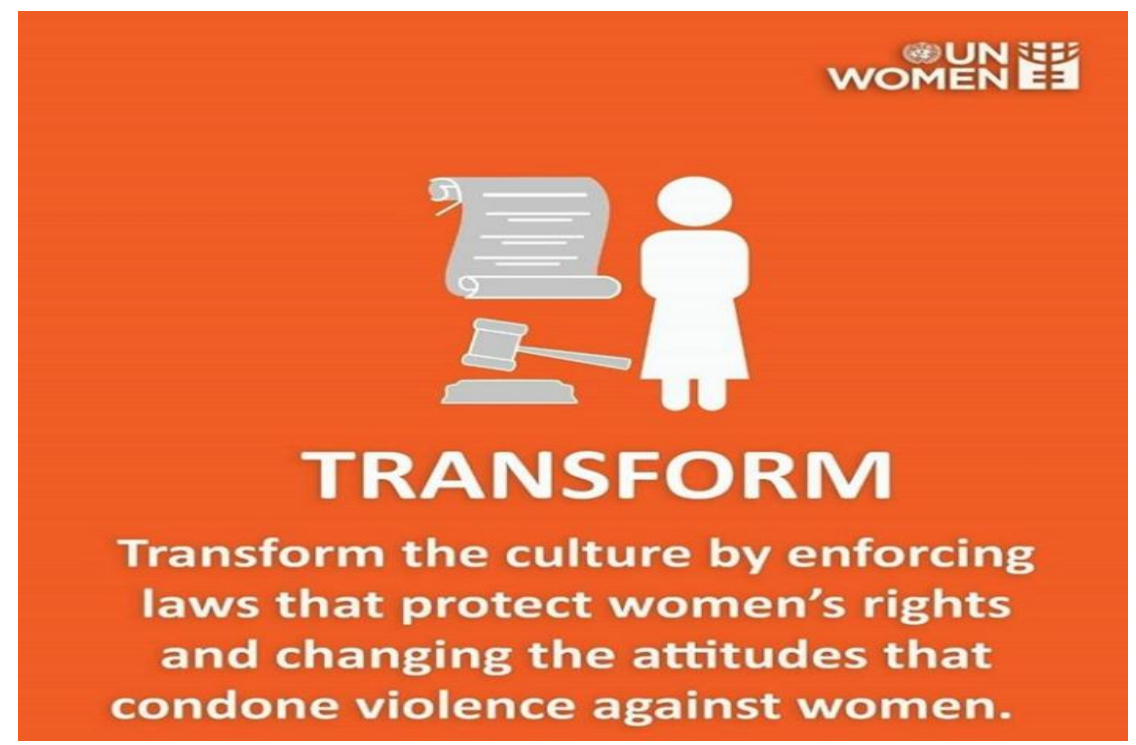

Poster 2 .https://www.instagram.com/p/B6LzjggHdZk/?igshid=khq0u2bg2dso

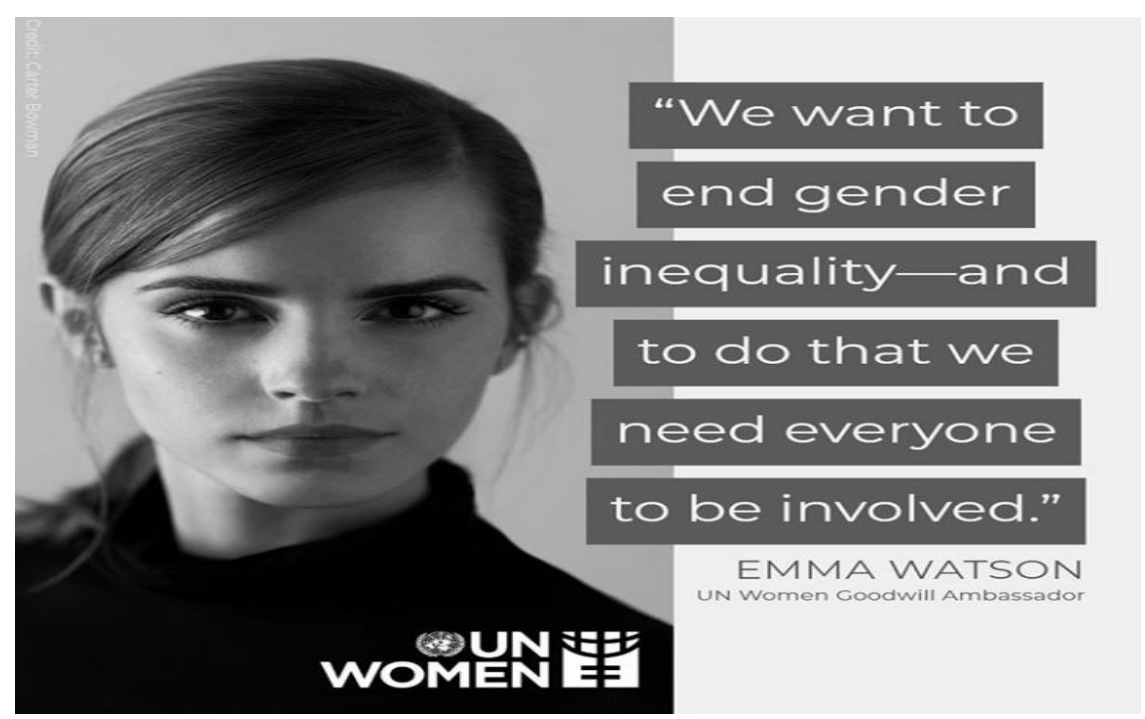

Poster 3. https://www.instagram.com/p/BwQ-5hSABNF/?igshid=qw1um6zg1vlh

\section{REFERENCES}

[1] Al-Masri, H. (2016). Jordanian editorial cartoons: a multimodal approach to the cartoons of Emad Hajjaj. Language and Communication, 50: 45-58.

[2] Chandler, D. (2002). Semiotics: the Basics. London and New York: Routeldge.

[3] Coffman, J. (2003). Lessons in Evaluating Communications Campaigns: Five Case Studies. Cambridge: Harvard Family Research Project.

[4] Eco, U. (1976). Theory of Semiotics. Bloomington: Indiana University Press.

[5] Halliday, M. (1994). An Introduction to Functional Grammar. London: Edward Arnold.

[6] Hu, C. and Luo, M. (2016). A multimodal discourse analysis of Tmall's Double Eleven advertisement. English Language Teaching, 9 (8): 156-169.

[7] Hunt, D. (2015). The many faces of diabetes: a critical multimodal discourse analysis of diabetes pages on Facebook. Language and Communication, 43: 72-86.

[8] Kress, G. and Van Leeuwen, T. (1996). Reading Images: The Grammar of Visual Design London and New York: Routeldge.

[9] Kress, G. and Van Leeuwen, T. (1998). Front pages: The (critical) analysis of newspaper layout. In Bell. A and Garrett P. (eds). Approaches to Media Discourse. Oxford: Blackwell, pp.186-219.

[10] Kress, G. and Van Leeuwen, T. (2006). Reading Images: the Grammar of Visual Design. London: Routledge.

[11] Lamb, B. (1997). The Good Campaigns Guide. London: NCVO Publications.

[12] Lirola, M. (2016). Multimodal analysis of a sample of political posters in Ireland during and after the Celtic Tiger. Revista Signos, 49(91): 245-267.

[13] Ma, J. and Stahl, L. (2017). A multimodal critical discourse analysis of an anti-vaccination information on Facebook. Library and Information Science Research, 39 (4): 303-310.

[14] Machin, D. (2007). Introduction to Multimodal Analysis. London: Hodder Arnold Publication. 
[15] Tan, S. and O'Halloran, K. and Wignell, P. and Chai, K. and Lange, R. (2018). A multimodal mixed methods approach for examining recontextualisation patterns of violent extremist images in online media. Discourse, Context \& Media, 21: 18-35.

[16] United Nations. (1993). Declaration on the Elimination of Violence against Women. Retrieved October 10, 2019 from https://www.ohchr.org/EN/ProfessionalInterest/Pages/ViolenceAgainstWomen.aspx.

[17] Van Leeuwen, T. (2015). Multimodality. In Deborah, T, Heidi, H, andDeborah, S. (eds.).The Handbook of Discourse Analysis. Oxford: Blackwell, pp. 447-465.

Souad, A. Belgrimet is an Algerian PhD candidate in the Department of English Language and Literature at the University of Jordan. Her research interests are discourse analysis and teaching English as a Foreign/Second Language.

Ghaleb, A. Rabab'ah is a Professor of Linguistics at the University of Sharjah. He has published many papers in Linguistics, Applied Linguistics and ESL in international journals, such as Journal of Pragmatics, Poznan Studies in Contemporary Linguistics, Journal of Psycholinguistic Research, JALT CALL Journal, Journal of Politeness Research and Research in Language. He is a member of the editorial board of two Scopus indexed journals, namely, International Journal of Arabic-English Studies (IJAES) and Jordan Journal of Modern Languages and Literature (JJMLL). 